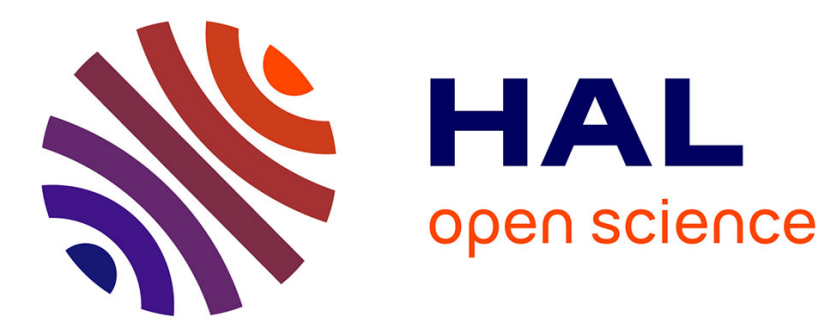

\title{
Financement des actions forestières en 1973
}

Jean Pardé

\section{To cite this version:}

Jean Pardé. Financement des actions forestières en 1973. 1973, pp.80-80. 10.4267/2042/20711 . hal-03395712

\section{HAL Id: hal-03395712 \\ https://hal.science/hal-03395712}

Submitted on 22 Oct 2021

HAL is a multi-disciplinary open access archive for the deposit and dissemination of scientific research documents, whether they are published or not. The documents may come from teaching and research institutions in France or abroad, or from public or private research centers.
L'archive ouverte pluridisciplinaire HAL, est destinée au dépôt et à la diffusion de documents scientifiques de niveau recherche, publiés ou non, émanant des établissements d'enseignement et de recherche français ou étrangers, des laboratoires publics ou privés. 
C'est au C.N.R.F. que résident deux "chefs de département" de l'I.N.R.A. : le chef du département des recherches forestières, et le chef du département de biométrie et de calcul automatique.

Complété par un arboretum (12 ha, en voie d'extension), des pépinières (plusieurs hectares) et des centaines d'hectares de places d'expériences en forêts, il constitue maintenant un outil de recherche entièrement neuf, et de classe internationale.

J. PARDÉ

\section{FINANCEMENT DES ACTIONS FORESTIËRES EN 1973 PAR LE SERVICE DES FORÊTS}

1973

I. Programme finalisé " Defense des forêts contre l'incendie en région méditerranéenne "

- Travaux d'entretien ................

- Interventions diverses . . . . . . . . . . . .

- Sapeurs forestiers .................

- Acquisitions, travaux ..............

- Anciens harkis ..................

- Subventions d'équipement $\ldots \ldots \ldots \ldots \ldots$.

Total

\section{Acquisitions}

- Acquisition d'espaces verts forestiers ......

- Acquisition par l'Etat de forêts et de terres à boiser $\ldots \ldots \ldots \ldots \ldots \ldots \ldots \ldots \ldots$

Total

III. Restauration de terrains en montagne

- Travaux d'entretien ..................

- Etudes, acquisitions, travaux ............

- Subventions d'équipement ............

Total

IV. Conversion en futaie feuillue

V. Réalisation d'équipements de certaines forêts en vue des loisirs et de la récréation.

VI. Inventaire forestier

VII. Versement à l'Office national des forêts, compensation des frais de garderie et de gestion des forêts des collectivités publiques ....

VIII. Autres actions : études, fixation de dunes, améliorations pastorales, rénovation rurale, forêts des départements d'Outre-mer . .......

IX. Pour mémoire Fonds forestier national (environ) ........................................

TOTAL DES MOYENS FINANCIERS (environ)

$$
\begin{array}{r}
11000000 \\
9000000 \\
\hline 20000000
\end{array}
$$

2995244

10800000

3000000

16755244

5000000

12202828

2800000

123199946

104199946

12654571

$\frac{180000000}{430000000} \quad \frac{176000000}{394000000}$

11456543

2747244

10500000

15848244

5000000

14052828

2300000

394000000
2600000 